\title{
REDES SOCIAIS E CONEXÕES PROVÁVEIS ENTRE MIGRAÇÕES INTERNAS E EMIGRAÇÃO INTERNACIONAL DE BRASILEIROS
}

\author{
Weber Soares \\ Roberto Nascimento Rodrigues
}

\begin{abstract}
Resumo: O artigo apresenta evidências das conexões prováveis da migração interna e a emigração internacional entre Governador Valadares e Ipatinga e as demais microrregiões brasileiras, com base na aplicação dos princípios teóricos e metodológicos da análise de redes sociais.

Palavras-chave: Migração internacional. Migração interna. Análise de redes sociais.

Abstract: This article shows evidences of the probable connections between the internal and international migration among the micro-regions of Governador Valadares and Ipatinga and the others micro-regions of Brazil, based on the social network analysis.

Key words: International migration. Internal migration. Social network analysis.
\end{abstract}

$\mathrm{E}$

ntre o final do século 19 e início do século 20, o Brasil recebeu grande quantidade de imigrantes oriundos principalmente de Portugal, da Itália, da Espanha, da Alemanha e do Japão. De meados do século 20 até final dos anos 70, o país manteve-se praticamente fechado a trocas populacionais externas. Na década de 80 , o Brasil volta a apresentar fluxos expressivos de migração internacional: exporta, nessa década, de 1 milhão a 2,5 milhões de pessoas (CARVALHO, 1996). E, quanto ao movimento populacional, assume um perfil emigratório.

O processo bipolar de distribuição espacial interna da população brasileira, que ganhara corpo durante o período 1930-70 pela enorme transferência de população do meio rural para o urbano (em especial para as metrópoles), e pelas migrações que se dirigiram às fronteiras agrícolas, passa por transformações significativas, nos anos 80. Entre as transformações sofridas pelas trajetórias espaciais dominantes no período $1940-80$ cabe pôr em relevo:
- a redução do volume dos fluxos migratórios;

- o maior peso das migrações de curta distância e intraregionais;

- a maior incidência das migrações de retorno; e

- a alteração da tendência à concentração urbana nas grandes capitais e regiões metropolitanas.

O objetivo deste artigo é tratar de colocar em evidência as conexões prováveis entre a migração interna e a migração internacional na história recente dos deslocamentos espaciais da população brasileira. Essas conexões expressam-se com maior precisão tanto na descoberta dos nós que, a um só tempo, integram a rede migratória interna e a rede migratória internacional, quanto nas resultantes de incorporação dos referidos nós a essa mesma rede. Para identificar tais conexões, foi acionado o arcabouço teórico e metodológico da Análise de Redes Sociais - ARS. Isso implica, por um lado, a recusa de uma espécie de representação metafórica das redes - presente em boa parte 
dos estudos que lidam com os fluxos migratórios - e, por outro lado, a necessidade de considerar as redes como método para descrição e análise dos padrões relacionais presentes em determinada configuração reticular. Subjacente à escolha da metodologia analítica de redes, está o pressuposto de que a ampliação dos laços interpessoais estimula a expressiva migração internacional que procede desses recortes territoriais - e é importante ressaltar que esses laços são suscitados pela magnitude das trocas migratórias entre os recortes territoriais brasileiros, uma vez que as redes sociais também migram (TILLY, 1990).

O passo analítico dado neste texto leva em conta a perspectiva copernicana das redes sociais. Isso significa considerar a rede migratória completa: todas as microrregiões (nós) e a ocorrência ou não de fluxos migratórios entre elas. A intenção reside, nesse caso, em identificar as microrregiões que:

- estão mais ou menos conectadas pela migração interna;

- são mais centrais;

- conferem mais estabilidade às estruturas reticulares; e

- ocupam posições similares na rede.

As trocas populacionais (imigrantes e emigrantes de última etapa migratória) nas 91 microrregiões brasileiras, nos períodos 1970-80 e 1981-91, constituem as "redes migratórias internas", que serão objeto de aplicação do arcabouço conceitual e metodológico da análise de redes. Nessas redes, as microrregiões representam os atores/nós, e os fluxos populacionais correspondem às conexões - e estas comportam sentido e intensidade.

Para estabelecer conexões entre os fluxos migratórios internos e a emigração internacional, a ênfase recairá sobre as microrregiões de Governador Valadares e Ipatinga, localizadas em Minas Gerais. A importância da migração internacional na dinâmica demográfica mineira, na valadarense e na ipatinguense torna-se evidente pela grandeza que ela representa no tocante às perdas líquidas ocorridas entre 1986 e 1991 . No estado, a migração internacional respondeu por cerca de $62 \%$ das perdas líquidas (172 mil, de 277 mil pessoas), em Valadares, por 50\% (12 mil, de 24 mil pessoas), e, em Ipatinga, por 90\% (11 mil, de 12 mil pessoas). Isto significa que a microrregião de Valadares e a microrregião de Ipatinga teriam contribuído com mais de $13 \%$ desse fluxo no período 1986-91, ainda que a população destas microrregiões representavam ao redor de 5\% da população estadual em 1991 (SOARES, 2002).
Quanto às informações sobre as características da emigração internacional de brasileiros, constituem referência básica os estudos de Martes (1999) e, em especial, de Soares (1995; 2002). Não se fará nenhuma exposição mais detalhada do fenômeno migratório internacional e esses estudos serão utilizados de acordo com sua estrita vinculação com o presente trabalho e como suporte às conclusões.

\section{ANÁLISE DE REDES: O OLHAR SOBRE AS RELAÇÕES}

Uma rede consiste num conjunto de atores ou nós (pessoas, objetos ou eventos) ligados por um tipo específico de relação. A diferentes tipos de relações correspondem redes diferentes - ainda que o conjunto de atores seja o mesmo. A rede, porém, não é consequiência, apenas, das relações que de fato existem entre os atores; ela é também o resultado da ausência de relações, da falta de laços diretos entre dois atores, daquilo que Burt (1992) chama de "buraco estrutural" (SCOTT, 2000).

As redes podem ser compostas por atores de natureza diversa. Num extremo, elas consistem de símbolos constantes em textos ou de símbolos presentes em verbalizações; noutro extremo, de estados que integram um país ou de países que compõem o sistema mundial. As redes podem, então, ser tão pequenas quanto uma sala de aula do ensino fundamental, ou tão grandes, como o conjunto dos países ${ }^{1}$ (HANNEMAN, 2001).

A organização do mundo social, com base em atributos, muito difere de uma organização que se debruça sobre as relações. "Atributos" são qualidades inerentes à unidade que não consideram as relações dessa mesma unidade com outras unidades ou com o contexto social específico dentro do qual essas qualidades são observadas. A construção de categorias a priori - que agrega indivíduos de acordo com sexo, idade, classe econômica, etc. - fundamenta-se no pressuposto de independência estatística (e, dessa forma, o pressuposto de dependência resultaria em um viés) e tem a intenção de determinar a força do relacionamento entre certas variáveis. Logo, a análise se faz sobre as relações entre variáveis - e não entre atores.

As relações entre os atores de uma rede apresentam forma e conteúdo. O conteúdo é dado pela natureza dos laços (parentesco, amizade, poder, troca de bens simbólicos ou materiais, afetiva, etc.); e a forma da relação compreende dois aspectos básicos: i) a intensidade ou a força 
do laço entre dois atores; e ii) a freqüência e o grau de reciprocidade com que esse laço se manifesta. Logo, conceitualmente, duas relações de conteúdo distinto podem apresentar formas idênticas (KNOKE; KUKLINSKI, 1982).

\section{Recortes Analíticos}

De acordo com Wellman (1997), a análise de redes considera, basicamente, duas perspectivas analíticas que se complementam:

- egocentrada (perspectiva ptolomaica) - nesse tipo de análise, a atenção está voltada para determinado nó/ator (ego) e outros nós/atores da rede com os quais o nó egóico mantenha relações. Logo, o número, a magnitude e a diversidade das conexões estabelecidas direta ou indiretamente com o ego definem os demais nós da rede;

- rede completa (perspectiva copernicana) - nesse tipo de análise, a informação sobre o padrão de laços entre todos os nós/atores na rede é usada, grosso modo, para identificar tanto subgrupos reticulares com maior grau de coesão interna quanto os nós que ocupam posições similares na rede.

Tendo em conta a rede completa (perspectiva copernicana), um passo capital da análise consiste em identificar as posições/papéis sociais que se manifestam pelo padrão das relações observadas entre os atores. A tarefa empírica consistiria, então, em distinguir os atores que apresentam maior semelhança, descrever o que os torna semelhantes, registrar o que os torna diferentes. É a relação entre os ocupantes de dois papéis que define o significado desses papéis (HANNEMAN, 2001).

\section{Redes Sociais, Redes Pessoais e Redes Migratórias}

A análise de redes atribui mais crédito à lógica da combinação do que à lógica puramente agregativa; sustenta que a configuração, assumida por uma rede qualquer, importa mais do que o acréscimo de uma relação extra ao conjunto de relações preexistentes. Não cabe dúvida sobre a importância das redes sociais para entender, em especial, os fluxos populacionais. Mas é necessário ir além dessa mera indicação e estabelecer as bases iniciais da perspectiva teórica que se estrutura em consequiência das imprecisões encontradas em parte da literatura sobre as temáticas redes sociais, redes pessoais e redes migratórias. Assim, cabe admitir que:
- Uma "rede social" consiste no conjunto de pessoas, organizações ou instituições sociais que estão conectadas por algum tipo de relação. Em virtude do processo em torno do qual ela se organiza, uma rede social pode abrigar várias redes sociais.

- Uma "rede pessoal" representa, então, um tipo de rede social que se funda em relações sociais de amizade, parentesco, etc.

- Uma "rede migratória" não se confunde com redes pessoais. Essas redes precedem a migração e são adaptadas a um fim específico: a ação de migrar. Quando suas singularidades dependem da natureza dos contextos sociais que ela articula, uma rede migratória é, também, um tipo específico de rede social que agrega redes sociais existentes e enseja a criação de outras: portanto, consiste em "uma rede de redes sociais". Por fim, uma "rede migratória" implica origem e destino - isto é: recortes territoriais, países, estados, microrregiões, municípios, cidades, etc. que se articulam por intermédio de fluxos migratórios.

\section{Representação Gráfica e Matricial das Redes}

A análise de redes retira os instrumentos para representar os padrões de laços entre os atores sociais de dois subcampos da matemática: a teoria dos grafos e a álgebra matricial.

O tipo de grafo utilizado para representar as redes sociais recebe o nome de "sociograma". No sociograma, os pontos/nós equivalem a atores, e os segmentos de linhas correspondem a laços (WASSERMAN; FAUST, 1994; SCOTT, 2000; HANNEMAN, 2001). De acordo com o tipo, esses laços classificam-se em: não-direcionados - registram a existência ou não de conexões entre pares de nós; direcionados - indicam que as conexões apresentam orientação de um nó para outro (a seta presente na extremidade de cada segmento de linha dá o sentido de cada conexão); e valorados - expõem a força das conexões entre os nós, expressa por valor numérico. É possível, ainda, representar graficamente laços que são, por exemplo, não-orientados e valorados, orientados e valorados, etc.

Os sociogramas constituem meio muito útil de representação das redes sociais. Todavia, quando o número de atores/nós é muito grande e os laços são muitos, torna-se quase impossível identificar visualmente os padrões relacionais. A solução está em representar as informações de rede na forma matricial. Assim, para sintetizar e revelar 
padrões existentes nas redes, podem ser realizadas operações matemáticas vinculadas ao campo da álgebra vetorial e da matricial (inversas, transpostas, adição, subtração, multiplicação e multiplicação booleana de matrizes).

Noções fundamentais sobre a estrutura reticular admitem maior precisão quando o padrão de laços entre um conjunto de atores é expresso formalmente por meio de grafos e matrizes. Consoante a teoria dos grafos e a álgebra matricial, vários são os conceitos, as medidas e os métodos utilizados para descrever as propriedades básicas, a centralidade e a centralização, além da divisão de determinada rede (WASSERMAN; FAUST, 1994; BONANICH, 2000; HANNEMAN, 2001). Assim, o passo seguinte consiste em lançar mão do recorte empírico sobre o qual esse arcabouço conceitual e metodológico da análise de redes deve ser aplicado: redes migratórias internas de 1970-80 e 1981-91. Para trabalhar os dados relacionais fluxos migratórios internos - numa linguagem estatística adequada, foi utilizado o programa Ucinet 5.0, para Windows.

O tamanho das redes migratórias de ambos os períodos resultou do agrupamento sem reposição das microrregiões brasileiras que mantiveram o maior volume de trocas populacionais internas com as microrregiões de Valadares e de Ipatinga: 91 ao todo. A associação das regularidades nas trocas migratórias entre as microrregiões - sistema empírico - com as regularidades matemáticas e topológicas que representam esse mesmo sistema empírico ganha expressão em duas matrizes quadradas $(91 \times 91)$ : a rede migratória 1 corresponde ao período 1970-80; e a rede migratória 2, ao período 1981 91. É preciso ter claro que a discriminação dessas trocas populacionais internas em duas redes migratórias distintas consiste em mero recurso analítico que prima pela identificação de tendências. Com efeito, é mais acertado supor a existência de uma rede migratória interna única, sujeita a alterações ao longo do tempo - pelo que registra Soares (2002) sobre a natureza processual, dinâmica das redes sociais.

Ambas as redes são valoradas, direcionadas e assimétricas. São valoradas porque cada uma das células matriciais traz um valor em $\mathrm{N}$ (conjunto dos números naturais) que corresponde, a um só tempo, ao de emigrantes de determinada microrregião e ao número de imigrantes em outra. São direcionadas porque uma microrregião pode receber ou não migrantes, e pode enviar ou não migrantes para outra microrregião - o que confere assimetria às matrizes, às redes migratórias.

\section{APLICAÇÃO DO ARCABOUÇO CONCEITUAL E METODOLÓGICO DA ANÁLISE DE REDES}

O tamanho de uma rede social é dado pela quantidade de nós que a integra. As redes migratórias dos períodos 1970-80 e 1981-91 possuem o mesmo número de nós: 91 microrregiões, o que equivale a 8.190 pares ordenados, isto é, 8.190 conexões diretas possíveis (vínculos migratórios) entre as microrregiões, duas a duas (Tabela 1). Embora de mesmo tamanho, a composição dos nós da rede migratória de 1970 a 1980 mostra-se diferente em comparação com a de 1981 a 1991: um total de 22 microrregiões foram substituídas de um período para outro. Houve aumento da participação do número de microrregiões dos estados de Rondônia, Minas Gerais, São Paulo e Espírito Santo; e queda da contribuição das microrregiões do Pará, Bahia, Paraná, Mato Grosso e Rio de Janeiro.

\section{TABELA 1}

Conexões Efetivas, Conexões Possíveis e Densidade das Redes Migratórias das Microrregiões Brasileiras que Mantiveram o Maior Volume de Trocas Populacionais com as Microrregiões de Valadares e Ipatinga Brasil - 1970-1991

\begin{tabular}{lcc}
\hline Indicadores & $1970-80$ & $1981-91$ \\
\hline Conexões Efetivas & 5.583 & 5.286 \\
Conexões Possíveis & 8.190 & 8.190 \\
Densidade (média) & 0,68 & 0,65 \\
Desvio-Padrão & 0,47 & 0,48 \\
Coeficiente Variação & 68,4 & 74,1 \\
\hline
\end{tabular}

Fonte: IBGE. Censos Demográficos 1970, 1980 e 1991.

Para informar a densidade, os dados foram dicotomizados de tal maneira que indicassem, apenas, a existência ou não de trocas migratórias entre uma microrregião e outra. A Tabela 1 mostra que a razão entre o número de conexões diretas - existentes entre parte das microrregiões que constituem a rede migratória do período 1970-80 - e o possível de conexões (densidade) foi de aproximadamente $68 \%$. Essa densidade sofre pequeno declínio na rede no período $1981-91$, pois $65 \%$ de todas as conexões possíveis estão presentes nesse caso. Assim, o nível geral das conexões, tanto nesta quanto naquela rede, deve ser considerado alto, pois ocorrem trocas migratórias entre mais da metade dos pares ordenados de cada uma das redes.

O agrupamento das microrregiões, conforme o fluxo máximo nas conexões resultantes das trocas migratórias 
da década de 70, indica que o primeiro nível de agregação é ocupado por Belo Horizonte, São Paulo e Valadares: essas três microrregiões apresentaram vínculos migratórios análogos entre si e com as demais microrregiões da rede. Brasília, Rio de Janeiro, Goiânia, Vitória, Osasco, Campinas, Ipatinga e Caratinga também são incorporados a esse subconjunto da metade dos pares ordenados de cada uma das redes.

O agrupamento das microrregiões, conforme o fluxo máximo nas conexões resultantes das trocas migratórias da década de 70, indica que o primeiro nível de agregação é ocupado por Belo Horizonte, São Paulo e Valadares: essas três microrregiões apresentaram vínculos migratórios análogos entre si e com as demais microrregiões da rede. Brasília, Rio de Janeiro, Goiânia, Vitória, Osasco, Campinas, Ipatinga e Caratinga também são incorporados a esse subconjunto de microrregiões.

Na rede migratória do período 1981-91, a representação gráfica da análise de cluster, baseada no fluxo máximo, torna evidente as microrregiões que, no tocante aos vínculos migratórios, mais se assemelham: Belo Horizonte e São Paulo, seguidas por Rio de Janeiro, Campinas, Brasília, Vitória, Valadares, Belo Horizonte, São Paulo, Ipatinga e São José dos Campos.

Portanto, o fluxo máximo deixa registrada a elevada conectividade entre Valadares, Ipatinga, Belo Horizonte, São Paulo, Rio de Janeiro, Vitória, Goiânia e Brasília nas duas redes migratórias internas: a de 1970-80 e a de 198191. Também assinala a conectividade que se manifesta tanto nas trocas populacionais ocorridas entre essas microrregiões quanto nas trocas populacionais que se deram entre essas microrregiões e a quase totalidade das outras microrregiões que integram ambas as redes migratórias.

A proeminência relativa de um ator/nó em relação à sua vizinhança (centralidade local) é dada pelo grau de centralidade. As microrregiões que se encontram em posição vantajosa na rede migratória de $1970-80$ por possuírem o maior número de conexões diretas/adjacentes (conseqüência dos fluxos populacionais de saída) são Valadares e São Paulo (Tabela 2). Em posição subseqüente, Belo Horizonte e Rio de Janeiro mantiveram conexões diretas com 98,9\% das microrregiões da rede; Teófilo Otoni, com 96,7\%; Ipatinga e Brasília, com 94,4\%; Vitória, com 93,3\% ; e Caratinga, com 90\%. Castanhal e Viseu, no Pará, e Cocoal, em Rondônia, ficaram com os menores graus de centralização dessa rede.

As microrregiões que mantiveram mais conexões diretas em relação aos fluxos populacionais de entrada
TABELA 2

Conexões e Grau de Centralidade na Rede Migratória das Dez Microrregiões Brasileiras que Mantiveram mais Volume de Trocas Populacionais com as Microrregiões de Valadares e Ipatinga Brasil - 1970-80

\begin{tabular}{lccccr}
\hline \multirow{2}{*}{ Microrregiões } & \multicolumn{2}{c}{ Conexões } & & \multicolumn{2}{c}{ Grau de Centralidade } \\
\cline { 2 - 3 } \cline { 5 - 6 } Teófilo Otoni & Saída & Entrada & & Saída & Entrada \\
Belo Horizonte & 89 & 68 & & 96,7 & 75,6 \\
Governador Valadares & 90 & 83 & & 100,0 & 92,2 \\
Ipatinga & 85 & 79 & & 94,4 & 87,8 \\
Caratinga & 81 & 59 & & 90,0 & 65,6 \\
Vitória & 84 & 86 & & 93,3 & 95,6 \\
Rio de Janeiro & 89 & 87 & & 98,9 & 96,7 \\
São Paulo & 90 & 90 & & 100,0 & 100,0 \\
Goiânia & 79 & 86 & & 87,8 & 95,6 \\
Brasília & 85 & 88 & & 94,4 & 97,8 \\
& & & & 100,0 \\
Média & 61,4 & 61,4 & & 68,2 & 68,2 \\
Desvio-Padrão & 17,4 & 16,0 & 19,3 & 17,8 \\
Mínimo & 21 & 22 & 23 & 24 \\
Máximo & 90 & 90 & 100 & 100 \\
Centralização & & & 0,32 & 0,32 \\
\hline
\end{tabular}

Fonte: IBGE. Censos Demográficos 1970 e 1980.

foram São Paulo e Belo Horizonte. Brasília e Rio de Janeiro constituíram, respectivamente, destino de pessoas oriundas de $97,8 \%$ e $96,7 \%$ das microrregiões da rede migratória de 1970-80; Goiânia e Vitória, de 95,6\%. Valadares, que recebeu migrantes de $92,2 \%$ dessa mesma rede, e Ipatinga, de 87,8\%, ocuparam, respectivamente, o sétimo e o nono lugar nessa hierarquia. Campos Sales, no Ceará, por ter mantido conexões de entrada com $22,4 \%$ das demais microrregiões, e Santa Tereza, no Espírito Santo, com 32,2\%, comportaram os menores graus de centralidade.

As estatísticas descritivas mostram que, em média, cada microrregião manteve conexões diretas, tanto em relação às entradas quanto às saídas migratórias, com 61,4 microrregiões da rede de 1970-80. A dispersão dos fluxos foi baixa: o desvio padrão situou-se abaixo da média para os ganhos e perdas populacionais.

A amplitude de coesão de toda a rede de 1970-80 em torno de atores/nós focais (centralização) foi baixa para ambos os tipos de conexões migratórias: o grau de centralização correspondente aos fluxos de entrada e de saída foi cerca de $32 \%$. Assim, as vantagens posicionais não se manifestaram tão desigualmente distribuídas entre as 
microrregiões - de fato, a distribuição dos migrantes de acordo com as microrregiões de destino e de origem não se concentrou em torno de uma microrregião ou pequeno aglomerado de microrregiões.

O maior número de conexões referente às perdas populacionais da rede migratória de 1981-91 ocorreu em Belo Horizonte e São Paulo (Tabela 3). Nesse período, o Rio de Janeiro manteve ligações diretas com 98,9\% das microrregiões integrantes dessa rede; Brasília e Vitória, com 95,6\%; Teófilo Otoni, com 91,1\%; e Goiânia e Caratinga, com $83,3 \%$. Valadares, que enviou pessoas para $93,3 \%$, e Ipatinga, para $88,9 \%$ da rede, detiveram o quarto e o sexto lugar na ordem decrescente de fluxos relacionais. Alvorada d'Oeste, em Rondônia, e Cárceres, no Mato Grosso, registraram os menores graus de centralidade.

Quanto aos fluxos de entrada, Belo Horizonte e São Paulo receberam migrantes de todas as microrregiões da rede no período 1981-91. As conexões diretas mantidas com 97,8\% dessa rede situaram o Rio de Janeiro e Campinas logo a seguir na hierarquia dos vínculos baseados em ganhos populacionais. Brasília, Vitória e Goiânia re-

TABELA 3

Conexões e Grau de Centralidade na Rede Migratória das Onze Microrregiões Brasileiras que Mantiveram mais Volume de Trocas Populacionais com as Microrregiões de Valadares e Ipatinga Brasil - 1981-91

\begin{tabular}{|c|c|c|c|c|}
\hline \multirow{2}{*}{ Microrregiões } & \multicolumn{2}{|c|}{ Conexões } & \multicolumn{2}{|c|}{ Grau de Centralidade } \\
\hline & Saída & $\overline{\text { Entrada }}$ & Saída & Entrada \\
\hline Teófilo Otoni & 82 & 62 & 91,1 & 68,9 \\
\hline Belo Horizonte & 90 & 90 & 100,0 & 100,0 \\
\hline Governador Valadares & 84 & 83 & 93,3 & 92,2 \\
\hline Ipatinga & 80 & 81 & 88,9 & 90,0 \\
\hline Caratinga & 75 & 53 & 83,3 & 58,9 \\
\hline Vitória & 86 & 84 & 95,6 & 93,3 \\
\hline Rio de Janeiro & 89 & 88 & 98,9 & 97,8 \\
\hline Campinas & 80 & 88 & 88,9 & 97,8 \\
\hline São Paulo & 90 & 90 & 100,0 & 100,0 \\
\hline Goiânia & 75 & 78 & 83,3 & 86,7 \\
\hline Brasília & 86 & 86 & 95,6 & 95,6 \\
\hline Média & 58,1 & 58,1 & 64,5 & 64,5 \\
\hline Desvio-Padrão & 15,9 & 15,6 & 17,7 & 17,3 \\
\hline Mínimo & 16 & 22 & 18 & 24 \\
\hline Máximo & 90 & 90 & 100 & 100 \\
\hline Centralização & & & 0,36 & 0,36 \\
\hline
\end{tabular}

Fonte: IBGE. Censos Demográficos 1980 e 1991. ceberam, respectivamente, pessoas oriundas de 95,6\%, $93,3 \%$ e $86,7 \%$ das microrregiões da rede migratória. $\mathrm{O}$ quinto e o sexto lugar foram ocupados por Valadares $92,2 \%$ e Ipatinga 90,0\%, respectivamente. As microrregiões que responderam pelo menor número de conexões migratórias de entrada no período 1981-91 foram Tauá, no Ceará, e Bocaiúva, em Minas Gerais.

As estatísticas descritivas informam que o número de conexões diretas estabelecido por cada microrregião na rede migratória de 1981-91 foi de aproximadamente 58. Também nesse caso a dispersão dos fluxos foi baixa: o desvio padrão seja para ganhos seja para perdas migratórias foi bem inferior à média.

O grau de centralização, quase $36 \%$, tanto para os vínculos de entrada quanto de saída, indica que a distribuição dos migrantes conforme as microrregiões de destino e de origem dos fluxos não se concentrou em torno de uma microrregião ou de um pequeno agrupamento de microrregiões.

O grau de proximidade acusa a posição estratégica de um ator/nó com relação à estrutura total da rede. Ou seja, essa medida de centralidade global considera os laços indiretos entre os atores/nós. Na rede migratória de 197080 , os fluxos migratórios de saída levam ao conhecimento de que Valadares e São Paulo situam-se na posição mais central (Tabela 4). Ocupando posições subseqüentes nessa ordem global de centralidades, Belo Horizonte e Rio de Janeiro despontam com um grau de proximidade de 98,9\%; Teófilo Otoni, de 96,8\%; Ipatinga e Brasília, de 94,7\%; Vitória, de 93,8\%; Caratinga, de 90,9\%; e Goiânia, de $89,1 \%$. Castanhal, no Pará, e Cocoal, em Rondônia, admitiram os menores graus de proximidade.

Em relação aos fluxos migratórios de entrada, a Tabela 4 assinala que as microrregiões mais centrais, no período 1970-80, foram Belo Horizonte e São Paulo. Os graus de proximidade de Brasília (97,8\%), do Rio de Janeiro (96,8\%), de Goiânia e de Vitória $(95,7 \%)$ situam essas microrregiões em posições subseqüentes na hierarquia de centralidades. Valadares e Ipatinga, com proximidade em relação às demais microrregiões da rede perto de $93 \%$ e de $89 \%$, ficaram na sétima e na nona posição, nessa mesma hierarquia. Pela centralidade mais baixa, foram responsáveis Campos Sales, no Ceará, e Santa Tereza, no Espírito Santo.

A dispersão dos dados em torno das médias correspondentes aos vínculos relacionais de entrada e de saída mostrou-se muito baixa. É o que se verifica nos valores assumidos pelo desvio padrão dos ganhos e das perdas 
TABELA 4

Conexões e Grau de Proximidade na Rede Migratória das Dez Microrregiões Brasileiras que Mantiveram mais Volume de Trocas Populacionais com as Microrregiões de Valadares e Ipatinga Brasil - 1970-80

\begin{tabular}{|c|c|c|c|c|}
\hline \multirow{2}{*}{ Microrregiões } & \multicolumn{2}{|c|}{ Conexões } & \multicolumn{2}{|c|}{ Grau de Proximidade } \\
\hline & Saída & Entrada & Saída & Entrada \\
\hline Teófilo Otoni & 112 & 93 & 80,4 & 96,8 \\
\hline Belo Horizonte & 90 & 91 & 100,0 & 98,9 \\
\hline Governador Valadares & 97 & 90 & 92,8 & 100,0 \\
\hline Ipatinga & 101 & 95 & 89,1 & 94,7 \\
\hline Caratinga & 121 & 99 & 74,4 & 90,9 \\
\hline Vitória & 94 & 96 & 95,7 & 93,8 \\
\hline Rio de Janeiro & 93 & 91 & 96,8 & 98,9 \\
\hline São Paulo & 90 & 90 & 100,0 & 100,0 \\
\hline Goiânia & 94 & 101 & 95,7 & 89,1 \\
\hline Brasilia & 92 & 95 & 97,8 & 94,7 \\
\hline Média & 118,6 & 118,6 & 77,3 & 77,4 \\
\hline Desvio-Padrão & 16,0 & 17,4 & 10,6 & 10,9 \\
\hline Mínimo & 90 & 90 & 57,0 & 56,6 \\
\hline Máximo & 158 & 159 & 100 & 100 \\
\hline Centralização & & & 0,462 & 0,459 \\
\hline
\end{tabular}

Fonte: IBGE. Censos Demográficos 1970 e 1980

populacionais. O grau de centralização, baseado nas distâncias geodésicas resultantes das conexões migratórias de entrada e de saída, gravitou ao redor de $46 \%$.

A aplicação do algoritmo - que considera a proximidade topológica, o grau de proximidade à rede migratória de 1981-91 - revela Belo Horizonte e São Paulo como microrregiões mais centrais quanto a perdas populacionais (Tabela 5). A seguir, obedecendo à hierarquia de centralidades, apresentaram-se Rio de Janeiro (98,9\%), Brasília e Vitória (95,7\%), Teófilo Otoni (91,8\%), Goiânia e Caratinga $(85,7 \%)$. Os laços de saída de Valadares e de Ipatinga, regidos por uma proximidade de $93,8 \%$ e 90,0\%, respectivamente, conferiram a essas microrregiões a quarta e a sexta posição nessa mesma hierarquia. Os menores graus de proximidade foram registrados nas microrregiões de Tucumã, no Pará, e Alvorada d'Oeste, em Rondônia.

Quanto aos ganhos populacionais, as microrregiões que detiveram a maior centralidade no período 1981-91 foram Belo Horizonte e São Paulo (Tabela 5). Em ordem decrescente dos graus de proximidade, seguem Rio de Janeiro e Campinas $(97,8 \%)$, Brasília $(95,7 \%)$, Vitória $(93,8 \%)$ e Goiânia $(88,2 \%)$. Valadares, titular de uma pro- ximidade de quase $93 \%$ em referência às microrregiões dessa rede, e Ipatinga, de 90,9\%, detiveram o quinto e sexto lugar, nessa ordem. Tauá, no Ceará, e Bocaiúva, em Minas Gerais, ficaram com os valores correspondentes às centralidades mais baixas.

A dispersão dos dados em torno do grau médio de proximidade, não só para as perdas como para os ganhos migratórios, é bem pequena: o desvio padrão, mais uma vez, ficou abaixo da média. O indicador de afastamento da distribuição das centralidades da rede de 1981-91 em comparação com a rede de formato estelar do mesmo tamanho, com grau de centralização de cerca de 51\%, traz à tona uma desigualdade superior à apresentada pela rede de 1970-80 na distribuição das vantagens posicionais - não só em relação aos laços de entrada, mas também no tocante aos laços de saída.

Quando se analisam as trocas populacionais nas redes migratórias de 1970-80 e de 1981-91 é necessário lançar mão do algoritmo Conjunto Lambda para identificar os subgrupos de microrregiões que mais estabilidade conferem a essas estruturas reticulares.

TABELA 5

Conexões e Grau de Proximidade na Rede Migratória das Onze Microrregiões Brasileiras que Mantiveram mais Volume de Trocas Populacionais com as Microrregiões de Valadares e Ipatinga Brasil - 1981-91

\begin{tabular}{|c|c|c|c|c|}
\hline \multirow{2}{*}{ Microrregiões } & \multicolumn{2}{|c|}{ Conexões } & \multicolumn{2}{|c|}{ Grau de Proximidade } \\
\hline & Saída & Entrada & Saída & Entrada \\
\hline Teófilo Otoni & 118 & 98 & 76,3 & 91,8 \\
\hline Belo Horizonte & 90 & 90 & 100,0 & 100,0 \\
\hline Governador Valadares & 97 & 96 & 92,8 & 93,8 \\
\hline Ipatinga & 99 & 100 & 90,9 & 90,0 \\
\hline Caratinga & 127 & 105 & 70,9 & 85,7 \\
\hline Vitória & 96 & 94 & 93,8 & 95,7 \\
\hline Rio de Janeiro & 92 & 91 & 97,8 & 98,9 \\
\hline Campinas & 92 & 100 & 97,8 & 90,0 \\
\hline São Paulo & 90 & 90 & 100,0 & 100,0 \\
\hline Goiânia & 102 & 105 & 88,2 & 85,7 \\
\hline Brasília & 94 & 94 & 95,7 & 95,7 \\
\hline Média & 121,9 & 121,9 & 75,1 & 75,1 \\
\hline Desvio-Padrão & 15,6 & 15,9 & 10,1 & 10,0 \\
\hline Mínimo & 90 & 90 & 57,0 & 54,9 \\
\hline Máximo & 158 & 164 & 100 & 100 \\
\hline Centralização & & & 0,506 & 0,506 \\
\hline
\end{tabular}

Fonte: IBGE. Censos Demográficos 1980 e 1991. 
A representação gráfica da análise de cluster para a rede da década de 70 põe à mostra, no primeiro nível de agregação, o agrupamento constituído por Governador Valadares, Brasília, Belo Horizonte, Rio de Janeiro e São Paulo. O movimento seguinte incorpora Ipatinga, Vitória, Teófilo Otoni e Osasco. Posteriormente, Goiânia e Caratinga passam a fazer parte do grupo. As conexões estabelecidas entre essas microrregiões são de capital importância. Afinal, tendo em vista o papel que desempenham na configuração/ continuidade dos fluxos migratórios, a remoção dessas microrregiões levaria à ruptura de toda a rede. Já as microrregiões que menos importam ao tecido de conexões da rede migratória da década de 70 são Castanhal, no Pará; Campos Sales, no Ceará; e Santa Tereza, no Espírito Santo.

A configuração assumida pelos dados resultantes da aplicação do algoritmo Lambda Set aos fluxos populacionais do período 1981-91 inscreve Valadares, Belo Horizonte, Rio de Janeiro e São Paulo no primeiro nível de agregação, seguidas por Brasília, Campinas, Vitória, Ipatinga, Goiânia, Osasco, Teófilo Otoni e Caratinga. Verifica-se que essas microrregiões ocupavam, na rede dos anos 70, os níveis mais altos de agregação. Conseqüentemente, caso Valadares, Belo Horizonte, Rio de Janeiro, São Paulo, Brasília, Campinas, Vitória e Ipatinga fossem retiradas de quaisquer das duas redes, ocorreria a maior obstrução das trocas migratórias. Assentadas nos níveis mais afastados de agregação do período 1981-91, encon- travam-se as microrregiões de: Cárceres, no Mato Grosso; Tucumã, no Pará; e Bocaiúva, em Minas Gerais.

Quando os dados são valorados, o coeficiente de correlação de Pearson constitui o algoritmo mais apropriado para subdividir determinada rede segundo o critério de equivalência estrutural com a finalidade de identificar os atores que guardam padrão similar de vínculos relacionais e que ocupam posições semelhantes na rede. Esse coeficiente varia de -1 (significa que dois atores possuem padrões de laços opostos com outros atores/nós) a 1 (indica que dois atores possuem o mesmo padrão de laços com outros atores/nós - equivalência estrutural perfeita).

A Tabela 6, que traz os coeficientes de correlação de Pearson para os pares de microrregiões da rede migratória de 1970-80, revela padrões similares de vínculos migratórios internos entre Valadares, Ipatinga, Caratinga, Vitória, Rio de Janeiro, Goiânia e Brasília: em tais casos, quase todos os coeficientes assumiram valores acima de 0,6. Em relação a cada uma dessas microrregiões, São Paulo foi depositária do padrão de laços migratórios menos semelhante: de fato, os pares microrregionais São Paulo/Rio de Janeiro e São Paulo/Belo Horizonte, por exemplo, evidenciam correlações negativas (-0,58 e -0,49 respectivamente). Logo, com exceção de Teófilo Otoni, nenhuma das outras microrregiões guarda equivalência estrutural com São Paulo. Tal fato se deve à posição singular da microrregião paulista nessa rede migratória: por

TABELA 6

Coeficiente de Correlação de Pearson na Rede Migratória das Dez Microrregiões Brasileiras que Mantiveram mais Volume de Trocas Populacionais com as Microrregiōes de Valadares e Ipatinga Brasil - 1970-80

\begin{tabular}{|c|c|c|c|c|c|c|c|c|c|c|}
\hline \multirow[b]{2}{*}{ Microrregiões } & \multicolumn{9}{|c|}{ Microrregiões } & \multirow[b]{2}{*}{ Brasília } \\
\hline & $\begin{array}{l}\text { Teófilo } \\
\text { Otoni }\end{array}$ & $\begin{array}{c}\text { Belo } \\
\text { Horizonte }\end{array}$ & $\begin{array}{l}\text { Governador } \\
\text { Valadares }\end{array}$ & Ipatinga & Caratinga & Vitória & $\begin{array}{l}\text { Rio de } \\
\text { Janeiro }\end{array}$ & São Paulo & Goiânia & \\
\hline Teófilo Otoni & 1,00 & 0,27 & 0,45 & 0,56 & 0,75 & 0,47 & 0,19 & 0,71 & 0,52 & 0,57 \\
\hline Belo Horizonte & & 1,00 & 0,69 & 0,71 & 0,61 & 0,73 & 0,78 & $-0,49$ & 0,77 & 0,64 \\
\hline Governador Valadares & & & 1,00 & 0,74 & 0,66 & 0,76 & 0,67 & $-0,07$ & 0,77 & 0,81 \\
\hline Ipatinga & & & & 1,00 & 0,72 & 0,79 & 0,77 & 0,06 & 0,77 & 0,73 \\
\hline Caratinga & & & & & 1,00 & 0,68 & 0,59 & 0,31 & 0,72 & 0,68 \\
\hline Vitória & & & & & & 1,00 & 0,72 & $-0,1$ & 0,76 & 0,76 \\
\hline Rio de Janeiro & & & & & & & 1,00 & $-0,58$ & 0,73 & 0,56 \\
\hline São Paulo & & & & & & & & 1,00 & $-0,13$ & 0,13 \\
\hline Goiânia & & & & & & & & & 1,00 & 0,76 \\
\hline Brasília & & & & & & & & & & 1,00 \\
\hline
\end{tabular}

Fonte: IBGE. Censos Demográficos 1970 e 1980. 
ser um locus privilegiado de expansão das atividades industriais no Brasil, São Paulo - e em especial sua região metropolitana - tornou-se o destino predominante dos principais fluxos migratórios internos nos anos 70 . Todavia, o fato de Teófilo Otoni ter apresentado padrão tão semelhante de laços com a microrregião de São Paulo causa estranheza e aponta para a necessidade de uma análise futura mais atenta.

O período 1981-91, apresenta padrões mais altos de similaridade dos fluxos migratórios internos entre Valadares, Ipatinga, Caratinga, Vitória, Rio de Janeiro e Goiânia do que os encontrados para a década de 70 (Tabela 7). Os coeficientes de Pearson para essas microrregiões, tomadas duas a duas, são superiores a 0,7 . Merece atenção especial o grau mais acentuado que tal tendência assume em relação a Teófilo Otoni. De um período para outro, as correlações sofrem um aumento significativo; e, quanto aos vínculos migratórios, inscrevem essa microrregião em um nível mais elevado de equivalência estrutural com Belo Horizonte $(r=0,78)$, Valadares $(r=0,79)$, Ipatinga $(r=0,84)$, Caratinga $(\mathrm{r}=0,84)$, Vitória $(\mathrm{r}=0,82)$ e Goiânia $(\mathrm{r}=0,8)$. No período 1981-91, São Paulo permanece com um padrão mais similar de laços; e Brasília assiste à redução dos valores de quase todos os coeficientes de Pearson - exceção feita ao caso do Rio de Janeiro, em que o coeficiente passa de 0,5 na década de 70 para 0,84 nos anos 80 .
Enfim, a similaridade do padrão de vínculos relacionais entre Valadares, Ipatinga, Caratinga, Vitória, Goiânia e Belo Horizonte foi alta em ambos os períodos, seja 1970-80, seja 1981-91. Portanto, essas microrregiões ocupam posições semelhantes nas duas redes migratórias internas e possuem a maioria ou todos os vínculos migratórios com as mesmas microrregiões que integram tais redes.

\section{DISCUSSÃO}

Considerando-se a perspectiva da rede social completa em fluxos migratórios internos dos períodos 1970-80 (rede migratória 1) e 1981-91 (rede migratória 2), a aplicação do arcabouço teórico e metodológico da análise de redes mostrou que o nível geral das conexões (densidade), tanto nesta como naquela, foi alto.

Essa alta densidade ganha ressonância na existência de distâncias geodésicas para todos os pares de microrregiões e nos pequenos valores (distâncias geodésicas) por elas assumido nas duas redes migratórias. De fato, qualquer microrregião, em ambos os períodos, está conectada por fluxos migratórios que descrevem uma seqüência máxima de dois passos.

Tanto na rede migratória de 1970-80 como na rede de 1981-91, a perspectiva analítica trazida pelo fluxo máximo deixa ver que Belo Horizonte, São Paulo, Rio de Janeiro, Valadares, Ipatinga, Brasília, Vitória e Campinas

TABELA 7

Coeficiente de Correlação de Pearson na Rede Migratória das Dez Microrregiões Brasileiras que Mantiveram mais Volume de Trocas Populacionais com as Microrregiões de Valadares e Ipatinga Brasil - 1981-91

\begin{tabular}{|c|c|c|c|c|c|c|c|c|c|c|}
\hline \multirow[b]{2}{*}{ Microrregiões } & \multicolumn{9}{|c|}{ Microrregiões } & \multirow[b]{2}{*}{ Brasília } \\
\hline & $\begin{array}{l}\text { Teófilo } \\
\text { Otoni }\end{array}$ & $\begin{array}{c}\text { Belo } \\
\text { Horizonte }\end{array}$ & $\begin{array}{c}\text { Governador } \\
\text { Valadares }\end{array}$ & Ipatinga & Caratinga & Vitória & $\begin{array}{l}\text { Rio de } \\
\text { Janeiro }\end{array}$ & São Paulo & Goiânia & \\
\hline Teófilo Otoni & 1,00 & 0,78 & 0,79 & 0,84 & 0,84 & 0,82 & 0,66 & 0,45 & 0,8 & 0,42 \\
\hline Belo Horizonte & & 1,00 & 0,72 & 0,73 & 0,72 & 0,73 & 0,58 & 0,48 & 0,75 & 0,39 \\
\hline Governador Valadares & & & 1,00 & 0,76 & 0,85 & 0,83 & 0,73 & 0,03 & 0,87 & 0,6 \\
\hline Ipatinga & & & & 1,00 & 0,77 & 0,83 & 0,59 & 0,49 & 0,78 & 0,38 \\
\hline Caratinga & & & & & 1,00 & 0,82 & 0,7 & 0,22 & 0,82 & 0,52 \\
\hline Vitória & & & & & & 1,00 & 0,7 & 0,3 & 0,81 & 0,5 \\
\hline Rio de Janeiro & & & & & & & 1,00 & $-0,37$ & 0,78 & 0,84 \\
\hline São Paulo & & & & & & & & 1,00 & $-0,04$ & $-0,73$ \\
\hline Goiânia & & & & & & & & & 1,00 & 0,67 \\
\hline Brasília & & & & & & & & & & 1,00 \\
\hline
\end{tabular}

Fonte: IBGE. Censos Demográficos 1980 e 1991. 
possuem vínculos migratórios análogos entre si e com as demais microrregiões da rede. Ou seja, um maior número de conexões diretas (alternativas) para alcançar outras microrregiões está à disposição dessas microrregiões.

Para as trocas populacionais dos dois decênios 1970-80 e 1981-91 - o indicador de centralidade local registrou que São Paulo, Belo Horizonte, Rio de Janeiro, Valadares, Ipatinga, Brasília e Vitória ocuparam posições centrais em ambas as redes, em razão do número de conexões diretas estabelecido por essas microrregiões. Já a amplitude de coesão das redes em torno de microrregiões focais (centralização) foi baixa para os dois tipos de conexões migratórias, ou seja, a distribuição dos migrantes de acordo com as microrregiões de destino e de origem não se restringiu a uma microrregião ou a um pequeno aglomerado de microrregiões.

Em relação aos fluxos de saída e de entrada de acordo com a medida de centralidade global (grau de proximidade), Belo Horizonte, São Paulo, Rio de Janeiro, Valadares, Ipatinga, Vitória, Goiânia e Brasília ficaram com as posições mais centrais em ambas as redes migratórias. Logo, quanto aos fluxos migratórios, essas microrregiões apresentam alto grau de acessibilidade. Isto quer dizer que são capazes de alcançar outras microrregiões - ou serem alcançadas por elas - por meio de passos de comprimento mais curto.

As medidas de centralidade põem à mostra a posição privilegiada e a proeminência de determinados nós na rede. Quando as relações são direcionadas, essa posição manifesta-se de duas formas: influência e prestígio. Neste caso, identificam-se os atores/nós que constituem o foco de recepção dos vínculos relacionais; naquele, os atores/nós que representam o centro desses vínculos. Assim, as altas centralidades locais e globais que Valadares, Ipatinga, Vitória, Brasília, São Paulo, Belo Horizonte e Rio de Janeiro apresentaram em relação às redes migratórias de 1970-80 e de 1981-91 permitem inferir tanto a influência quanto o prestígio dessas sete microrregiões no tocante às perdas e ganhos no âmbito das trocas populacionais ocorridas nesses períodos.

A utilização do algoritmo Lambda $\mathrm{Se}$ - como recurso para identificar os subgrupos de microrregiões que conferem mais estabilidade à rede e as microrregiões que tornam o tecido de conexões migratórias mais vulnerável à ruptura - evidenciou que Valadares, Ipatinga, Brasília, Belo Horizonte, São Paulo, Rio de Janeiro, Vitória e Goiânia participaram dos níveis mais altos de agregação em ambas as redes migratórias: tanto a de 1970-80 como a de 1981-91. Assim, as conexões que essas microrregiões estabeleceram entre si e com outras microrregiões reticulares são de importância capital para garantir a estrutura das trocas populacionais.

A aplicação do critério de equivalência estrutural às duas redes migratórias mostrou que a similaridade do padrão de vínculos relacionais entre Valadares, Ipatinga, Caratinga, Vitória, Goiânia, Belo Horizonte e Rio de Janeiro foi alta em ambos os períodos: Teófilo Otoni inscreve-se em nível elevado de equivalência estrutural com essas microrregiões nos anos 80. A teoria registra que atores/nós situados em posições reticulares semelhantes, em posições que são estruturalmente equivalentes, possuem a maioria ou todas as conexões com os mesmos atores/ nós da rede a que pertencem - e, por isso mesmo, monitoram-se reciprocamente. Assim, Valadares, Ipatinga, Caratinga, Vitória, Goiânia, Belo Horizonte, Rio de Janeiro e Teófilo Otoni, que se encontram em posições estruturais similares nas duas redes migratórias internas, estariam mais sensíveis a mudanças ocorridas no interior do subgrupo constituído por essas microrregiões do que às alterações sofridas por microrregiões que não fazem parte desse subgrupo.

\section{CONEXÕES PROVÁVEIS COM A EMIGRAÇÃO INTERNACIONAL}

Em suma, esse conjunto de medidas que toma como referência a perspectiva copernicana das redes sociais põe em evidência: i) um contexto reticular propício tanto à difusão de bens materiais e simbólicos quanto à circulação de representações sociais sobre a migração internacional (e isso acontece, por exemplo, quando se tem em conta a elevada conectividade das redes migratórias internas resultante da alta densidade e das pequenas distâncias geodésicas entre as microrregiões) e ii) também destaca microrregiões onde se situam as cidades brasileiras que maior participação tiveram na emigração internacional cujo destino foi o estado americano de Massachusetts. De fato, a seleção das microrregiões que constituem o resultado comum da aplicação das medidas de rede, fluxo máximo, centralidade local, centralidade global, conjuntos Lambda e equivalência estrutural, faculta o reconhecimento da coincidência entre o proeminente papel desempenhado por Valadares, Belo Horizonte, Rio de Janeiro, Ipatinga e Vitória nas redes migratórias internas, assim como a posição que ocuparam primeiro, segundo, terceiro, quinto e sexto lugar respectivamente - na hierarquia das dez cidades brasileiras que 
mais enviaram migrantes para Massachusetts, conforme

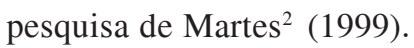

Quando se tem em conta:

- o registro numérico de que a microrregião de Ipatinga ocupou lugar de decisivo relevo nas trocas populacionais internas de Valadares, e que Valadares teve grande peso nas trocas populacionais ipatinguenses (SOARES, 2002);

- a importância da emigração internacional na dinâmica demográfica valadarense e na ipatinguense;

- o fato de que se encontram migrantes internacionais de Ipatinga nas mesmas localidades onde, nos Estados Unidos, residem os migrantes internacionais de Valadares visto que as pessoas não migram para qualquer lugar, mas sim para lugares onde possuem parentes ou amigos;

- a evidência de que os movimentos migratórios transplantam os principais segmentos de redes sociais; e

- as conexões históricas entre Valadares e Ipatinga.

Tudo isso leva a crer, à luz do princípio de que os fluxos migratórios facultam a ampliação dos laços pessoais e, em virtude disso, propiciam o aumento dos canais de transferência de recursos materiais, simbólicos, etc. na existência de vínculos estreitos entre a migração interna e a internacional de Valadares e de Ipatinga.

O perfil demográfico mais recente da migração internacional de Ipatinga (SOARES, 2002), sugere que a rede migratória internacional, originada em Valadares, ampliou seu campo de ação e incorporou a microrregião ipatinguense.

Além disso, ocorreu uma elevação das trocas migratórias internas entre Vitória, Valadares e Ipatinga da década de 70 para os anos 80 :

- o número de emigrantes de Valadares para a microrregião de Vitória aumentou 52\%, passou de 4.631 a 7.042;

- as perdas populacionais de Ipatinga para Vitória saltaram de 3.089 a 8.299;

- os imigrantes de Vitória em Valadares e Ipatinga também aumentaram de um período a outro, chegando a quase $199 \%$ no caso valadarense e a $78 \%$ no ipatinguense.

Tais dados remetem à intensificação dos contatos entre esses recortes territoriais brasileiros, à ampliação dos laços pessoais e à transferência de segmentos de redes sociais de uma microrregião para outra (SOARES, 2002). Desta forma, verifica-se a expressiva presença de emigrantes internacionais originários de Vitória nas cidades de Massachusetts, onde se concentraram os emigrantes internacionais de Valadares e de Ipatinga - Vitória ocupa o sexto lugar entre as dez cidades brasileiras que mais enviaram migrantes para esse estado americano (MARTES, 1999). De mais a mais, a expansão das relações socioeconômicas que a construção da Estrada de Ferro VitóriaMinas proporciona entre o Vale do Rio Doce - mais precisamente Valadares e Ipatinga -, e a capital do estado espírito-santense constituem fortes indícios de que essa mesma capital e a microrregião que ela polariza integram a rede migratória internacional que tem como nós Valadares e Ipatinga.

Concluindo, se o escrutínio dos fluxos populacionais internos, realizado por Soares (2002), segundo a perspectiva egocentrada da análise de redes, dá crédito à existência de vínculos estreitos entre as trocas migratórias internas e a emigração internacional de Valadares, de Ipatinga e de Vitória, também põe em relevo fortes indícios de que essas microrregiões constituem uma rede migratória internacional. Parece razoável supor que Belo Horizonte e Rio de Janeiro também se agregam a essa rede migratória internacional - em virtude das intensas trocas populacionais que mantiveram com Valadares e Ipatinga; da recorrência com que se manifestaram; e da proeminência que adquiriram em todos os resultados da aplicação das medidas de redes sociais com base na perspectiva copernicana.

Mas não se pode dizer o mesmo, por exemplo, de Caratinga: apesar de estar inscrita em alto nível de equivalência estrutural com Valadares e Ipatinga nas redes migratórias internas, e de ter sustentado intensas trocas populacionais com essas duas microrregiões mineiras, em ambos os períodos - 1970-80 e 1981-91 - a microrregião caratinguense não integrou o conjunto de cidades brasileiras que mais enviaram migrantes para Massachusetts. Entre as prováveis explicações para a não-inserção de Caratinga no fluxo migratório internacional, cabe lembrar que o ambiente social joga um papel efetivo na difusão de bens simbólicos e na circulação de representações sociais sobre a migração internacional. Isto é, o processo de transmissão de informação manifesta-se num campo de negociação avaliativo que transforma essa mesma informação. Conseqüentemente, os desdobramentos desse processo não apresentam necessariamente uma única via, visto que dependem da singularidade do contexto social no qual ele se desenvolve.

Finalmente, o conjunto de assertivas que gravitam em torno das conexões entre a emigração internacional e a migração interna deixa entrever uma via privilegiada de reflexão que se abre com os suportes teóricos e metodológicos da análise de redes sociais - à luz da análise da distribuição social das oportunidades e constrangimentos, 
da desigualdade de recursos disponíveis e da estrutura social por meio da qual as pessoas têm acesso ou não a esses mesmos recursos. As redes funcionam como circuito de tráfego no ambiente social, como trajetórias relacionais possíveis que ligam certos atores/nós; remetem ao fato de que a interação carece de princípios "ordenadores", de representações sociais por meio das quais as pautas de conduta possam ser exercidas e, até mesmo, mudadas. Elas são dinâmicas, suscetíveis de alterações ao longo do tempo e, portanto, possuem dimensão processual, histórica, uma vez que expressam as regularidades presentes nas interações sociais.

\section{NOTAS}

1. A título de ilustração, poder-se-ia considerar, como exemplo de rede, o fluxo comercial de 50 mercadorias diferentes (café, açúcar, chá, etc.) entre 170 países do sistema mundial, em determinado ano. Neste caso, os 170 países despontam como atores e a quantidade de cada mercadoria exportada de um país para os 169 restantes, como a força do laço existente entre eles (HANNEMAN, 2001).

2. Conforme pesquisa de campo realizada por Martes (1999), as dez cidades brasileiras que mais contribuíram com os fluxos migratórios internacionais para o estado americano de Massachusetts admitem a seguinte hierarquia: Valadares participou com $17 \%$ do total de emigrantes, Belo Horizonte com $11 \%$, Rio de Janeiro com $9 \%$, São Paulo com $8 \%$, Ipatinga com $6 \%$, Vitória com $5 \%$, Goiânia com $4 \%$, Anápolis com 3\%, Brasília com $3 \%$ e Criciúma com $2 \%$. Dignas de nota são as posições ocupadas por Ipatinga, quinto lugar, e por Vitória, sexto lugar, nesta hierarquia.

\section{REFERÊNCIAS BIBLIOGRÁFICAS}

BONANICH, P. Introduction mathematical sociology: a textbook. Irvine, 2000. Disponível em: <http://www.sscnet.ucla.edu/soc/ faculty/bonacich/textbook>. Acesso em: 14 set. 2001.

BURT, R.S. Structural holes: the social structure of competition. Cambridge: Harvard University Press, 1992.

CARVALHO, J.A.M. de. O saldo dos fluxos migratórios internacionais do Brasil na década de 80: uma tentativa de estimação. Revista Brasileira de Estudos de População, Campinas, v. 13, n. 1, p. 3-14, jan./jun. 1996.

DEGENNE, A.; FORSÉ, M. Introducing social networks. London: SAGE Publications, 1999. 248 p.

GOZA, F. A imigração na América do Norte. Revista Brasileira de Estudos de População, Campinas, v. 9, n. 1, p. 65-82, 1992.

HAMMEL, E.A. A Theory of Culture for Demography. Population and Development Review, v. 16, n. 3, p. 455-485, 1990.
HANNEMAN, R. Introduction to social network methods. Disponível em: <http://wizard.ucr.edu/ rhannema/ index.html\#news>. Acesso em: 21 jun. 2001.

KNOKE, D.; KUKLINSKI, J. Network Analysis. Beverly Hills: Sage Publications, 1982. 96 p.

KRITZ, M.M.; ZLOTNIK, H. Global interactions: migration systems, processes, and policies. In: KRITZ, M.M.; LIM, L.L.; ZLOTNIK, H. (Ed.). International migration systems: a global approach. Oxford: Claredon Press, 1992. p. 1-16.

MARGOLIS, M.L. Little Brazil: imigrantes brasileiros em Nova York. Campinas: Papirus, 1994. 452 p.

MARTES, A.C.B. Brasileiros nos Estados Unidos: um estudo sobre os imigrantes em Massachusetts. São Paulo: Paz e Terra, 1999. 208 p.

MASSEY, D.S. et al. Theories of international migration: a review and appraisal. Population and Development Review, v. 1, n. 1, p. 411-466, 1993.

et al. Return to Aztlan: The social process of international migration from western Mexico. Los Angeles: University of California Press, 1987. 335 p.

NACIONES UNIDAS. Migración internacional y desarrollo. Nueva York: Sección de Reproducción de las Naciones Unidas, 1997.

OLIVEIRA, O. de; STERN, C. Notas sobre a teoria da migração interna: aspectos sociológicos. In: MOURA, H. de. (Coord.). Migrações internas: textos escolhidos. Fortaleza, BNB/ETENE, t. 1, 1980. p. $248-265$.

PIORE, M. Birds of passage: Migrant labor and industrial societies. New York: Cambridge University Press, 1979.

PORTES, A. Economic sociology and the sociology of immigration: a conceptual overview. In: . (Ed.). The economy sociology of immigration: essays on networks, ethnicity and entrepreneurship. New York: Russell Sage Foundation, 1995. p. 1-41.

PORTES, A.; BACH, R.L. Latin journey: Cuban and Mexican immigrants in the United States. Berkeley: University of California, 1985.

SALES, T. Brasileiros longe de casa. São Paulo: Cortez, 1999. 232 p.

SALIM, C.A. Estrutura agrária e dinâmica migratória na região centro-oeste, 1970-80: análise do êxodo rural e da mobilidade da força de trabalho no contexto de industrialização da agricultura e da fronteira urbanizada. Tese (Doutorado em Demografia) - UFRJ, Rio de Janeiro, 1992.

SASSEN, S. The mobility of labor and capital. New York: Cambridge University Press, 1988.

SAYAD, A. O retorno, elemento constitutivo do migrante. Travessia - Revista do Migrante, São Paulo, jan. 2000 (número especial).

SCOTT, J. Social network analysis. London: SAGE, 2000.

SOARES, W. Da metáfora à substância: redes sociais, redes migratórias e migração nacional e internacional em Valadares e Ipatinga. Tese (Doutorado em Demografia) - UFRJ, Rio de Janeiro, 2002.

Emigrantes e investidores: redefinindo a dinâmica imobiliária na economia valadarense. Dissertação (Mestrado em Planejamento Urbano e Regional) - UFRJ, Rio de Janeiro, 1995.

TILLY, C. Transplanted Networks. In: YANS-Mc LAUGHLIN, V. (Ed.). Immigration Reconsidered. Oxford: Oxford University Press, 1990. p. 79-95. 
VALENTE, T.W. Network models of the diffusion of innovations. New Jersey: Hampton Press, 1995.

WASSERMAN, S.; FAUST, K. Social network analysis: methods and applications. Cambridge: Cambridge University Press, 1994. 825 p.

WELLMAN, B. What is social network analysis? Toronto, 1997. Disponível em: <http://www.ascusc.org/jcmc/vol3/issue/ garton.html>. Acesso em: 10 ago. 2001.
Weber SoAres: Professor do Departamento de Geografia da UFMG (weber@igc.gmail.com).

Roberto Nascimento Rodrigues: Professor do Departamento de Demografia da UFMG e Pesquisador do Centro de Desenvolvimento e Planejamento Regional - Cedeplar/UFMG (beto@cedeplar.ufmg.br).

Artigo recebido em 17 de março de 2005.

Aprovado em 6 de abril de 2005. 